\title{
Description of Immature Stages of Aegyptus rhynchophorus (Elbishlawy \& Allam), (Uropodina, Trachyuropodidae )
}

\author{
Sally F.M. Allam and Shahira M.O.El-Bishlawi \\ Dept. of Agricutural Zoology and Nematology.. Cairo Univ., Egypt, e-mail: Sallyfmalam@ hotmail.com \\ (Received: September 11, 2009)
}

\begin{abstract}
Great numbers of Aegyptus rhynchophorus ElBishlawi and Allam (Uropodina: Trachyuropodidae) were collected from cocoons, pupae and adults of Rhynchophorus ferrugineus (Olivier) (Coleoptera: Curculionidae) infesting palm trees in El-Sharkia and Ismailia, Egypt. Immature stages are described and illustrated.
\end{abstract}

Key Words: Survey Trachyuorpodidae, Uropodid mite, Immatures, Red palm weevil, Curculionidae, Egypt.

\section{INTRODUCTION}

The superfamily Uropodoidea includes more specialized members of the Uropodina. Species of the genera Uroobvella. Uropoda and Nenteria are found in manure and compost, while some of the genera Trematura and Urosieus are associated with stored products (Hughes, 1967). Members of the species Aegyptus rhynchophorus El-Bishlawi and Allam 2007 were found associated with pupae and adults of the red palm weevil, Rhynchophorus ferrugineus (Olivier) inside palm trees in Ismailia, Egypt. Mite Immature stages are described and illustrated.

\section{MATERIALS AND METHODS}

Last instar larvae, pupae and adults of $R$. ferrugineus were collected, using a hatchet, from the trunk of the infested palm trees in El-Sharkia and Ismailia gavernorate during spring, summer and fall. Captured insects were transferred to a special room at the same area to comply with quarantine laws during the experiment. The insects were observed, as every infested one had about 500-1000 mite individuals in the thorax region, abdomen and inner elytera. The pupae cocoons were ruptured and the mites were found on the pupae surfaces. Collected mite stages were cleared in Nesbitts solution, mounted in Hoyer's medium, and studied under light microscopy for morphological details. All measurements are taken in millimicrone $(\mu \mathrm{m})$. Nomenclature of morphological characters followed that of Evans and Till 1979 and Lindquest 2001.

\section{Description of $A$. rhynchophorus EL-Bishlawi \&} Allam immature stages

Larva: (Fig. 1) .Body ovate, creamy. $351 \pm 12.72 \mu \mathrm{m}$ long and, $242 \pm 1.41 \mu \mathrm{m}$ wide. Cheliceral digits dentate with a sclerotized node immediately behind base of movable chela.
Dorsum: (Fig. la) Shield entire anchor shape, decply sclerotized, with 9 pairs of simple setae and few transverse zones at posterior end.

Venter: (Fig.1b) Tritosternum with three terminal pilose laciniae; three pairs of sternal setae present and opisthogastric region with two pairs of simple setae.

Legs (Fig. 1c). All legs provided with well developed ambulacrum; distal end of tarsus I with 3 twirled setae; most setae spine like. Number of setae on legs I- IV as follows: coaxae 1-1-1, trochanters 3-4-3, femora7-3-3, genua 4-4-3, tibiae 3-4-3, tarsi 14-6-9.

Protonymph: (Fig. 2) Body ovate, yellowish. $428.5 \pm 58.68 \mu \mathrm{m}$ long and, $238 \pm 5.65 \mu \mathrm{m}$ wide. Tectum and chelicerae as in larva.

Dorsum: (Fig. 2a) with one podonotal shield, two mesonotal shields and one pygidial shield. Dorsum sclerotized as illustrated and with 32 pairs of simple setae and two pairs of pores.

Venter: (Fig. 2b) Tritosternum with three terminal pilose laciniae; sternal plate with three pairs of simple setae. Anal plate trapezoidal with two pairs of adanal setae. Opisthogastric region with three pairs of small simple setae.

Legs: Ambulacrum of leg I longer than those of legs II-IV; distal end of tarsus I and IV with a twirled seta, some setae on leg segments spin like. Number of setae on legs I-IV as follows: coxae 1-1-1-2, trochanters 3-3-1-3, femora 3-3-1-2, genua 3-3-3-3, tibiae 1-2-2-3-tarsi 16-9-7-11.

Phoretic deutonymph: (Fig. 3) Body oval yellowish, $620 \pm 28.28 \mu \mathrm{m}$ long and, $428 \pm 2.82 \mu \mathrm{m}$ wide, chelicera as that of larva. 


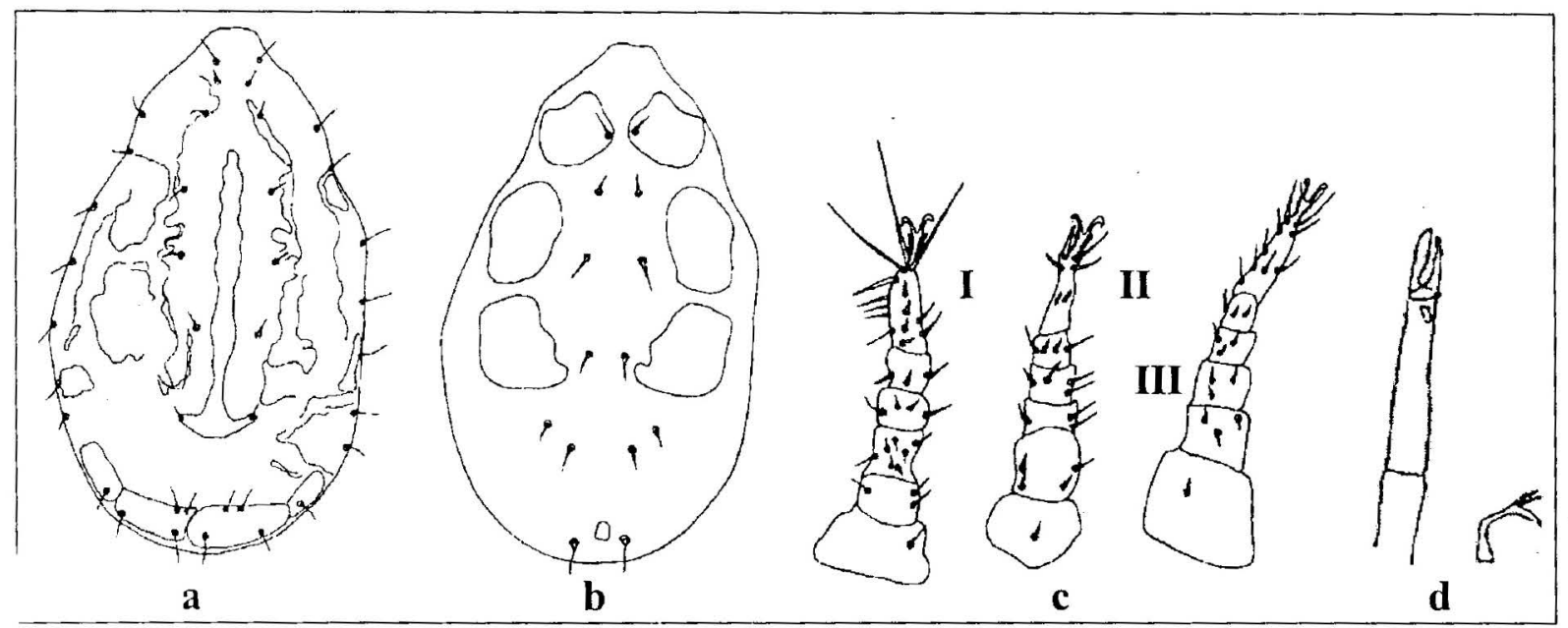

Fig. (1). Aegyptus rhynchophrus n.spn.G larva
a) dorsal.
b)ventral.
c) legs from I to III.
d) chelicera and tritosternum.

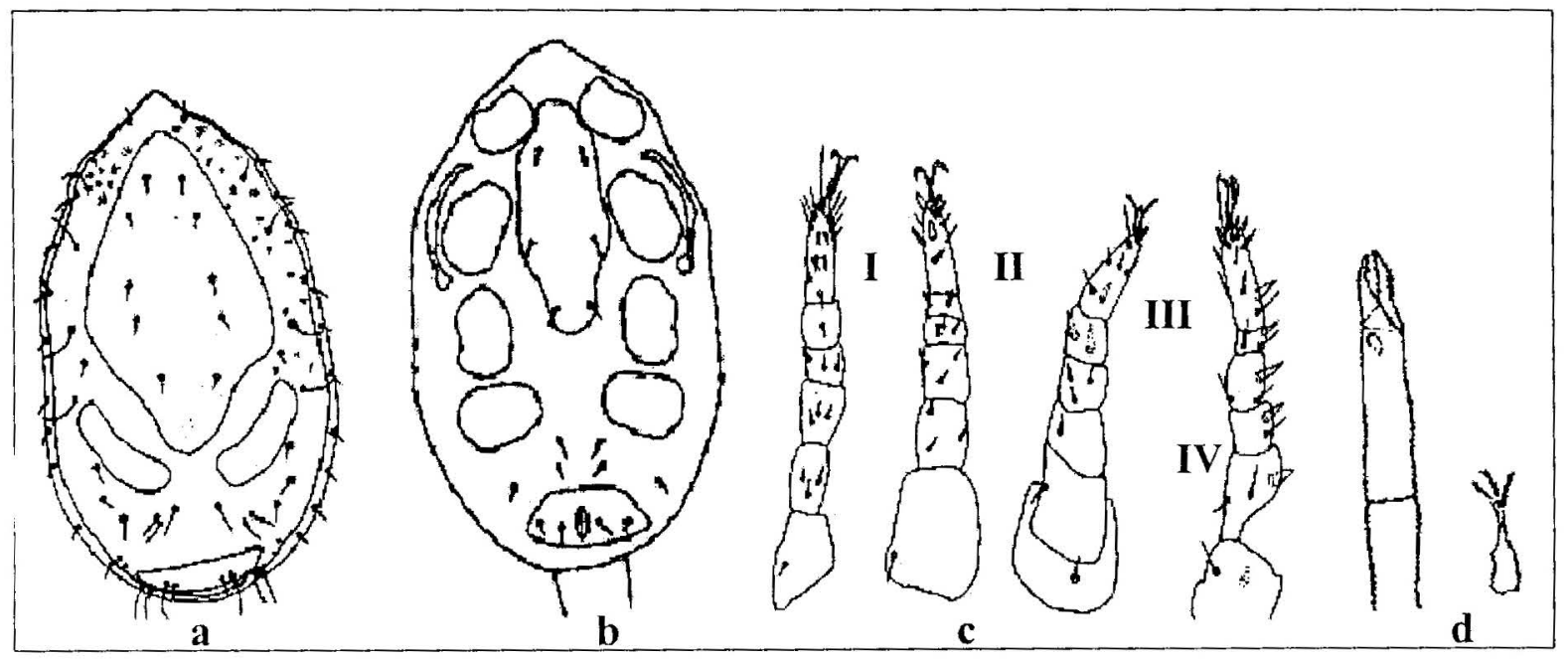

Fig. (2). Aegyptus rhynchophrus El-Bishlawi \& Allam protonymph
a) dorsum.
b) venter
c) legs I - IV.
d) chelicera and tritosternum.

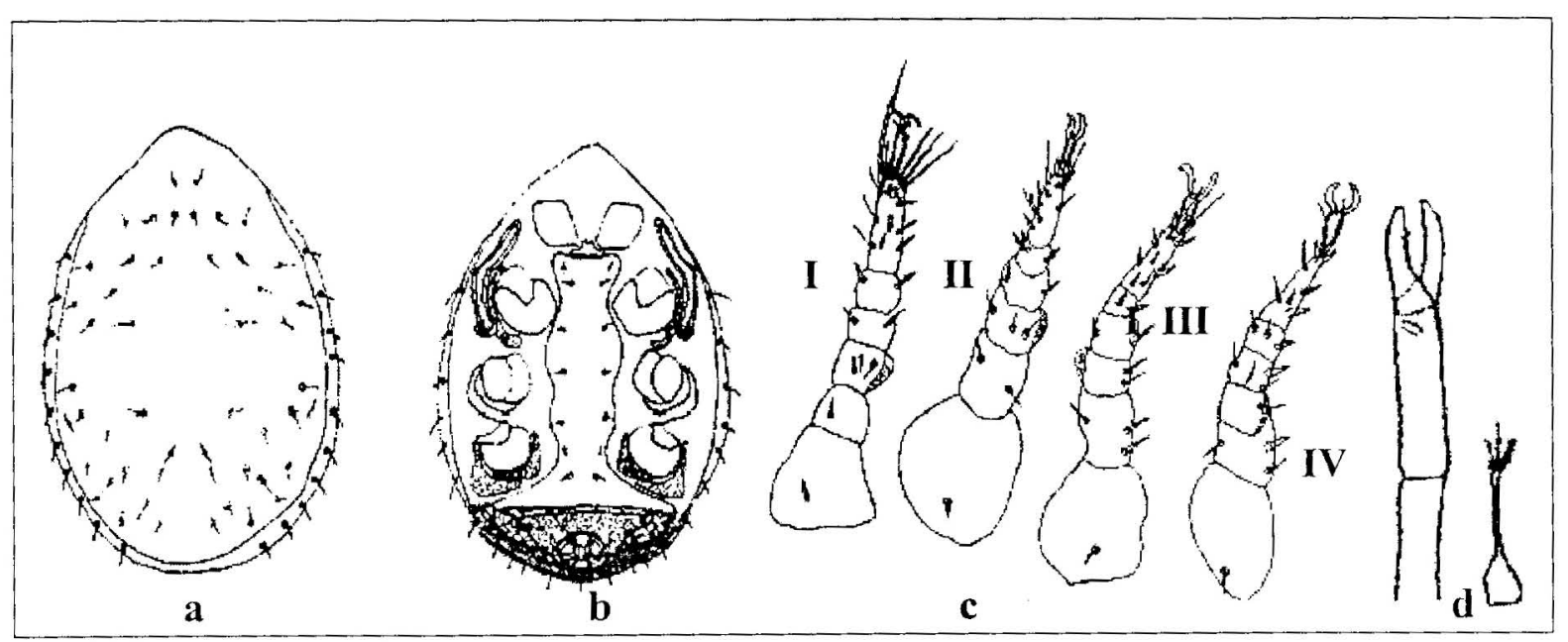

Fig. (3). Aegyptus rhynchophrus El-Bishlawi \& Allam deutonymph:
a) dorsum.
b) venter.
c) legs I - IV
d) chelicera and tritosternum. 
Dorsum: (Fig. 3a) With centrodorsal shield separated posteriorly and laterally; with 23 pairs of small simple setae, two pairs of lyrifissures and ten pairs of marginal setae. ( Fig.3a)

Venter: Tritosternum similar to that of protonymph. Sternogenital shield inverted $\mathrm{T}$ shape with five pairs of simple setae and two pairs of lyrifissures. Ventroanal shield nearly bowl shape, with three pairs of simple setae. Anal plate superimposed on the ventro - anal shield; two pairs of small simple setae on the anal valves. Opithogastric region with one pair of simple setae; 11 pairs of simple marginal setae present. Peritreme present between coxae II and III, peritremal plate uniconvolate with inner side zigzag shape - Endopodal, metapodal and exopodal plates present.

Legs: All legs provided with well developed ambulacrum; distal end of tarsi I,III and IV with twirled setae; some setae on leg segments spine like; each femur provided with a longitudinal crest.

Number of setae on legs I - IV as follows: coxae-
1-1-1-1, trochanters- 1-2-3-3, femora- 3-3-2-1, genua-2-2-2-3,tibiae-2-3-2-3,tarsi-17-12-12-11.

\section{REFERENCES}

El-Bishlawi, Shahira M.O. and Allam,Sally. F. M. 2007. Aegyptus rhynchophorus, N.GEN., N.SP. (Acari:Uropodina:Trachyuropodidae) from the red palm weevill, Rhynchophorus ferrugineus (Olivier), (Coleoptera, Curculionidae) In Egypt. Proc. $2^{\text {nd }}$ Inter.Conf.Ent. Soc.Egypt, 421-433

Evans, G. O. and W. M.Till .1979. Mesostigmatic mites of Britain and Ireland (Chelicerata: Acari Parasitiformes)-An introduction to their external morphology and classification, Trans.Zool. Soc. Lond., 35:139-270.

Hughes, A. M. 1976. The mites of stored food and houses. Minist.of Agric. Fish and Food.London., $176 \mathrm{pp}$.

Lindquist, E. E. 2001. Arthropods associated with livestock dung. Key to females of species of uropodoid mites associated with pestiferous flies in livestock dung in Canada. Internet., 1-19. 